\title{
NOTES
}

\section{Transfer of Halobacterium denitrificans (Tomlinson, Jahnke, and Hochstein) to the Genus Haloferax as Haloferax denitrificans comb. nov.}

\author{
B. J. TINDALL, ${ }^{1}+*$ G. A. TOMLINSON,${ }^{2}$ AND L. I. HOCHSTEIN ${ }^{3}$ \\ Institut für Mikrobiologe, Rheinische Friedrich-Wilhelms-Universität, Meckenheimer Allee 168, D-5300 Bonn 1, Federal \\ Republic of Germany ${ }^{1}$; Department of Biology, University of Santa Clara, Santa Clara, California $95053^{2}$; and National \\ Aeronautics and Space Administration, Ames Research Center, Moffet Field, California $94035^{3}$
}

\begin{abstract}
Halobacterium denitrificans (Tomlinson, Jahnke, and Hochstein) was described at a time when the taxonomic subdivision of the family Halobacteriaceae was in a state of flux. On the basis of both biochemical and chemotaxonomic data, this organism exhibits features which indicate that it is more closely related to members of the genus Haloferax. On the basis of such criteria, we propose that Halobacterium denitrificans be reclassified as Haloferax denitrificans comb. nov. The type strain is strain ATCC 35960 (= DSM 4425).
\end{abstract}

Halobacterium denitrificans was isolated from salterns in the southern part of San Francisco Bay by using techniques selective for extremely halophilic bacteria capable of nitrate reduction (17). At the time that Halobacterium denitrificans was described, only two nonalkaliphilic genera, Halobacterium and Halococcus, were recognized. Studies based on nucleic acid hybridization (12), polar lipids $(7,12,18)$, and biochemical tests (18) showed that the nonalkaliphilic members of the family Halobacteriaceae could be divided into a number of additional genera, for which the names Haloarcula and Haloferax were proposed (18). These two genera could easily be distinguished from one another and from existing taxa on the basis of their polar lipid compositions $(7$, $12,18)$. Biochemical and physiological differences between the two genera were also described by Torreblanca et al. (18), and these differences supported the chemotaxonomic data. Both of these new genera were also shown to contain organisms capable of nitrate reduction, although the mechanisms differ in different organisms $(4,9)$. Halobacterium denitrificans, like Haloferax mediterranei and Haloarcula vallismortis, was shown to be capable of producing gas from nitrates. However, Halobacterium denitrificans was the first member of the family Halobacteriaceae in which it was unambiguously shown that the organism grew by dissimilatory nitrate reduction under anaerobic conditions. Furthermore, the lipid data, the biochemical characteristics, and the absence of gas vacuoles showed that this bacterium did not belong in the taxon Haloferax mediterranei or the taxon Haloarcula vallismortis (17). When the genera Haloarcula and Haloferax were defined, the status of Halobacterium denitrificans was not taken into consideration, and it was the purpose of this study to clarify the generic status of this organism by using chemotaxonomic techniques.

Extraction of quinones and polar lipids. Quinones were extracted from freeze-dried cells as described previously (3, 14) and were analyzed by a combination of thin-layer chro-

\footnotetext{
* Corresponding author.

$\dagger$ Present address: DSM-Deutsche Sammlung für Mikroorganismen und Zellkulturen GmbH., Mascheroder Weg 1b, D-3300 Braunschweig, Federal Republic of Germany.
}

matography, ultraviolet spectroscopy, high-pressure liquid chromatography, and mass spectroscopy $(3,14)$. Authentic MK-8 (2-methyl-3-octaprenyl-1,4-naphthoquinone) and MK8(VIII-H ${ }_{2}$ ) (2-methyl-3-VIII-dihydrooctaprenyl-1,4-naphthoquinone) were obtained from Halococcus morrhuae CCM 859.

Polar lipids were extracted by using the modified method of Bligh and Dyer (1), and these lipids were subjected to thin-layer chromatography on silca gel thin layers in two dimensions or double development in one direction, as described previously $(7,15,16,18)$. Lipids were detected by using specific spray reagents $(15,16)$, and the presence of sulfate in lipids was detected by using the method of Kates (6). Appropriate standard polar lipids were obtained from Halobacterium cutirubrum NRC 34001, Haloferax mediterranei R-4, Haloarcula vallismortis CCM 3404, Halobacterium sodomense NCMB 2197, Halobacterium halobium NCMB 777, and Halobacterium cutirubrum NCMB 763. Squalenes were detected by thin-layer chromatography, followed by spraying with anisaldehyde $/ \mathrm{H}_{2} \mathrm{SO}_{4}(16)$.

Diether glycerol lipids were released from freeze-dried cells by acid hydrolysis and were subjected to thin-layer and gas chromatographic analysis as described by Tindall (13). 2,3-Di-O-phytanyl-sn-glycerol from Halobacterium cutirubrum NRC 34001 and the 2,3-di- $O$-phytanyl-sn-glycerol and 2-O-sesterterpanyl-3-O-phytanyl-sn-glycerol diether from Natronobacterium gregoryi SP2 were used as standards.

Examination of the quinone composition of Halobacterium denitrificans revealed the presence of MK-8 and MK$8\left(\right.$ VIII $\left.-\mathrm{H}_{2}\right)$ as the major components. The presence of MK8 (VIII- $\left.\mathrm{H}_{2}\right)$ has been shown to be a unique feature of members of the family Halobacteriaceae $(2,3,14 ; \mathrm{B}$. J. Tindall and M. D. Collins, unpublished data). Analysis of the diether lipid composition showed that the only ether-linked lipid present was a 2,3-di- $O$-phytanyl-sn-glycerol diether, excluding the strain examined from those taxa which contain more than one diether. The presence of tetrahydrosqualene as the major component among the $\mathrm{C}_{30}$ isoprenoids indicates that Halobacterium denitrificans belongs in the group of aerobic, extremely halophilic archaebacteria which produce this compound as the major isoprenoid, namely, the mem- 
bers of the genus Haloferax $(7,16,17)$. Examination of the polar lipids showed that four compounds were present, including two glycolipids and two phospholipids. The two phospholipids were identified as the diether derivatives of phosphatidylglycerol and phosphatidylglycerophosphate; no evidence was found for the presence of phosphatidylglycerosulfate. The two glycolipids were identified as a diglycosyl diether lipid and its sulfated derivative. On the basis of their $R_{f}$ values and staining behavior, these compounds were judged to be identical to the diglycosyl diether and sulfated diglycosyl diether previously identified in Haloferax mediterranei (8). The sulfated derivative was clearly separated from other glycolipids and sulfated glycolipids found in the other reference strains. On the basis of the chemotaxonomic data, it is obvious that Halobacterium denitrificans belongs in the genus Haloferax.

Studies on other members of the genus Haloferax have shown that the following three species may be differentiated: Haloferax mediterranei, Haloferax volcanii, and Haloferax gibbonsii $(5,10,11,18)$. Haloferax mediterranei is easily distinguished from the other two species since it contains gas vacuoles and is capable of anaerobic growth at the expense of nitrate reduction, with gas production. Haloferax volcanii and Haloferax gibbonsii do not contain gas vacuoles, and neither has been shown to be capable of anaerobic growth at the expense of nitrate, although Haloferax volcanii reduces nitrate to nitrite. Comparisons with Halobacterium denitrificans show that this strain is not gas vacuolate, but produces gas and grows anaerobically by using nitrate. Additional biochemical data show unambigously that there are distinct differences among Halobacterium denitrificans, Haloferax mediterranei, and Haloferax volcanii $(10,11,17)$, which support the transfer of Halobacterium denitrificans to the genus Haloferax as Haloferax denitrificans comb. nov.

Description of Haloferax dentrificans comb. nov. Gramnegative, aerobic, nonmotile pleomorphic cells $(0.8$ to 1.0 by 2.0 to $3.0 \mu \mathrm{m})$. Cells occur singly and exhibit a range of morphological forms, including disk-shaped cells. Gas vacuoles are not formed within the cells. Colonies on agar are 2 to $3 \mathrm{~mm}$ in diameter, round, convex, entire, and orangish red. Cells are halophilic, with growth occurring at $\mathrm{NaCl}$ concentrations between $1.5 \mathrm{M}$ and at least $4.5 \mathrm{M}$. Cells lyse in distilled water. The temperature range for growth is 30 to $55^{\circ} \mathrm{C}$ in the presence of $3.0 \mathrm{M} \mathrm{NaCl}$. The $\mathrm{pH}$ range is 6 to 8 , with an optimum at $\mathrm{pH} 6.7$ (at $37^{\circ} \mathrm{C}$ ). Cells grow aerobically in a mineral salts medium (containing $0.005 \%$ yeast extract and ammonium as the nitrogen source) containing D-glucose, D-galactose, D-fructose, maltose, sucrose, acetate, citrate, fumarate, glycerol, lactate, $\alpha$-ketoglutarate, malate, succinate, or pyruvate as the carbon source. Acidification of the medium occurs in unbuffered medium when growth occurs in the presence of sugars. Utilization of nitrate or nitrite occurs under anaerobic conditions. Nitrogen $\left(\mathrm{N}_{2}\right)$ is the sole produce when growth occurs in the presence of $0.1 \%$ (wt/ vol) nitrate. At higher concentrations nitrite, nitrous oxide, and nitrogen accumulate. Tween 40 and gelatin are hydrolyzed, and sulfide is produced from thiosulfate. Urea, starch, and Tween 80 are not hydrolyzed, and indole is not produced from tryptophan. Catalase and oxidase positive. The major isoprenoid neutral lipids present are tetrahydrosqualene and carotenoids of the bacterioruberin series. The major menaquinones present are MK-8 and MK-8(VIII- $\left.\mathrm{H}_{2}\right)$. Acid hydrolysis of whole cells releases a single diether component identical to 2,3-di- $O$-phytanyl-sn-glycerol. The major polar lipids are the diether analogs of phosphatidylglycerol, phosphatidylglycerophosphate, a diglycosyl glycerol diether, and its $6^{\prime}-\mathrm{SO}_{4}$-glycosyl-glycosyl-glycerol diether derivative. The type strain is strain ATCC 35960 (= DSM 4425). The characteristics of the type strain correspond to those of the species.

B.J.T. was supported by a grant from the Deutsche Forschungsgemeninschaft to $\mathrm{H}$. G. Trüper.

B.J.T. thanks Birgit Amendt for skilled assistance.

\section{LITERATURE CITED}

1. Bligh, E. G., and W. J. Dyer. 1959. A rapid method of lipid extraction and purification. Can. J. Biochem. Physiol. 7:911917.

2. Collins, M. D., R. M. Kroppenstedt, J. Tamaoka, K. Komagata, and T. Kinoshita. 1988. Structures of the tetrahydrogenated menaquinones from Actinomadura angiospora, Faenia rectivirgula, and Saccharothrix australiensis. Curr. Microbiol. 17: 275-279.

3. Collins, M. D., and B. J. Tindall. 1987. Occurrence of menaquinones and some novel methylated menaquinones in the alkaliphilic, extremely halophilic archaebacterium Natronobacterium gregoryi. FEMS Microbiol. Lett. 43:307-312.

4. Hochstein, L. I., and G. A. Tomlinson. 1985. Denitrification by extremely halophilic bacteria. FEMS Microbiol. Lett. 27:329331.

5. Juez, G., F. Rodriguez-Valera, A. Ventosa, and D. J. Kushner. 1986. Haloarcula hispanica spec. nov. and Haloferax gibbonsii spec. nov., two new species of extremely halophilic archaebacteria. Syst. Appl. Microbiol. 8:75-79.

6. Kates, M. 1978. The phytanylether-linked polar lipids and isoprenoid neutral lipids of extremely halophilic bacteria. Prog. Chem. Fats Other Lipids 15:301-342.

7. Kushwaha, S. C., G. Juez-Perez, F. Rodriguez-Valera, M. Kates, and D. J. Kushner. 1982. Survey of lipids of a new group of extremely halophilic bacteria from salt ponds in Spain. Can. J. Microbiol. 28:1365-1372.

8. Kushwaha, S. C., M. Kates, G. Juez, F. Rodriguez-Valera, and D. J. Kushner. 1982. Polar lipids of an extremely halophilic bacterial strain (R-4) isolated from salt ponds in Spain. Biochim. Biophys. Acta 711:19-25.

9. Mancinelli, R. L., and L. I. Hochstein. 1986. The occurrence of denitrification in extremely halophilic bacteria. FEMS Microbiol. Lett. 35:55-58.

10. Mullakhanbhai, M. F., and H. Larsen. 1975. Halobacterium volcanii spec. nov., a new Dead Sea Halobacterium with a moderate salt requirement. Arch. Microbiol. 104:204-214.

11. Rodriguez-Valera, F., G. Juez, and D. J. Kushner. 1983. Halobacterium mediterranei spec. nov., a new carbohydrateutilising extreme halophile. Syst. Appl. Microbiol. 4:369-381.

12. Ross, H. N. M., and W. D. Grant. 1985. Nucleic acid studies on halophilic archaebacteria. J. Gen. Microbiol. 131:165-173.

13. Tindall, B. J. 1985. Qualitative and quantitative distribution of diether lipids in haloalkaliphilic archaebacteria. Syst. Appl. Microbiol. 6:243-246.

14. Tindall, B. J., and M. D. Collins. 1986. Structure of 2-methyl3-VIII-dihydrooctaprenyl-1,4-napthoquinone from Halococcus morrhuae. FEMS Microbiol. Lett. 37:117-119.

15. Tindall, B. J., H. N. M. Ross, and W. D. Grant. 1984. Natronobacterium gen. nov. and Natronococcus gen. nov., two new genera of haloalkaliphilic archaebacteria. Syst. Appl. Microbiol. 5:41-57.

16. Tindall, B. J., G. S. Tomlinson, and L. I. Hochstein. 1987. Polar lipid composition of a new halobacterium. Syst. Appl. Microbiol. 9:6-8.

17. Tomlinson, G. A., L. L. Jahnke, and L. I. Hochstein. 1986. Halobacterium denitrificans sp. nov., an extremely halophilic denitrifying bacterium. Int. J. Syst. Bacteriol. 36:66-70.

18. Torreblanca, M., F. Rodriguez-Valera, G. Juez, A. Ventosa, M. Kamekura, and M. Kates. 1986. Classification of non-alkaliphilic halobacteria based on numerical taxonomy and polar lipid composition, and description of Haloarcula gen. nov. and Haloferax gen. nov. Syst. Appl. Microbiol. 8:89-99. 